\title{
Monte Carlo Analysis Using Pesticide Fate Models
}

\author{
Michael KLEIN \\ Fraunhofer-Institut für Umweltchemie und Ökotoxikologie, \\ D-57392 Schmallenberg, Germany
}

(Received November 20, 1998)

\begin{abstract}
The effect of the variation of climatic input parameters on the leaching of pesticides is presented in this study. Based on weather series with daily precipitation and temperature data over a period of 30 years for a total of 13 regions in Germany Monte-Carlo simulations using the computer model PELMO have been performed for spring as well as for autumn applications. The results show that independent on the region the fluctuations always decreased with increasing leaching potential. The geometric standard deviation for pesticide concentrations of $1.0 \mu \mathrm{g} / l$ was in the range of 1.6 to 2.4. However, simulations with an example pesticide demonstrated that the differences between different regions were of higher importance than differences due to variance of climate within a given region. It was concluded that the next generation of our information infrastructures needs to take into account the spatial component of input data.
\end{abstract}

Key words: PELMO, Monte-Carlo analysis, pesticide, leaching, pesticide registration, ground water.

\section{INTRODUCTION}

Presently, a number of computer models are used in Europe to assess the fate of pesticides in different compartments of the environment. Particularly in the field of ground water protection a lot of experience has been made with some models. ${ }^{1)}$ For example, the German authorities involved in the registration of pesticides ask for lysimeter studies dependent on the results of simulations performed with PELMO (Pesticide Leaching $\mathrm{Model}^{2,3)}$ ). As PELMO is a deterministic model it calculates the behaviour of substances for a specific singular situation (scenario) for which all input data must be given as unique values.

However, when comparing the results of deterministic computer models like PELMO with pesticide's fate in the real environment there is one important difference: a constant behaviour in nature will never be found; instead a spectrum of different results will be observed even if outdoor studies have been performed at the same location and the same time. This is caused by the fact that all important input data vary with space and time. To bring the output of the deterministic models more close to the situation in the environment the models can be extended to stochastic computer models. They consider not only unique input values but also their distribution in the environment. Considering the results of stochastic computer models, which are actually histograms of concentrations instead of singular values, the evaluation of stochastic model output might become one of the future instruments for the registration of pesticide.

In this paper results of a stochastic model called MCPELMO (Monte-Carlo Pesticide Leaching Model ${ }^{4,5)}$ ) is presented. MCPELMO is still based on the deterministic model PELMO but a specific shell that runs under $M S$-Windows was built around allowing the user to perform stochastic simulations for a number of regions.

\section{MATERIALS AND METHODS}

The idea of the Monte-Carlo approach is to consider the distribution of the input parameters like precipitation, temperature or organic carbon content in soil by using a special computer module that creates sets of input parameters randomly according to their distribution in the environment. After having performed a high number of simulations the interesting output (e.g. pesticide concentrations in the percolate) are analysed according to its distribution.

However, an enormous number of simulations have to be performed to get stable distributions of the output data, if all input scenario parameters are modified at the same time. Therefore, as a first step, in this project only the variation of the climate was taken into consideration. Nine locations in Germany, of which daily air temperature and precipitation were available for a period of 30 
years, have been selected as being representative for the various climatic conditions in Germany. ${ }^{6)}$ Some information on the different locations is given Table 1. Unfortunately, less information on the regional distribution of soil data was available. Table 2 shows some information on the soil types which have been used for the study.

It was expected that the extension of the climate fluctuations on the leaching of pesticides depends on the leaching potential of these substances. Therefore, three types of pesticides with different mean average concentrations in the percolate $(0.01,0.1$, and $1.0 \mu \mathrm{g} / \mathrm{l}$, none of them real products) were simulated for all 13 selected regions. Finally, the influence of spring and autumn application was analysed.
The simulation period for all calculations was 1015 years each with the same annual rate of application on the same year's day. However, for the Monte-Carlo analysis the first 15 ("warm-up") years were not taken into consideration.

As input parameters, PELMO needs air temperature, precipitation, and relative humidity in air for each day of simulation. In order to only use climate triple that really have been observed at this location no standard weather generator has been used for the Monte-Carlo simulations. For fixed time periods of one month the computer selected randomly a specific year from which the real daily weather data was taken (e.g. January 1975, February 1968, March 1984, ...).

All statistical evaluations were performed using the

Table 1 Annual precipitation $(\mathrm{mm})$ and air temperature $\left({ }^{\circ} \mathrm{C}\right)$ for representative locations in Germany.

\begin{tabular}{llccccc}
\hline No. & Location & $\begin{array}{c}\text { Mean } \\
\text { precipitation }\end{array}$ & $\begin{array}{c}\text { Standard } \\
\text { deviation }\end{array}$ & $\begin{array}{c}\text { Minimum } \\
\text { precipitation }\end{array}$ & $\begin{array}{c}\text { Maximum } \\
\text { precipitation }\end{array}$ & $\begin{array}{c}\text { Mean annual } \\
\text { temperature }\end{array}$ \\
\hline 1 & Schleswig & 926.2 & 145.5 & 591.6 & 1189.3 & 7.1 \\
2 & Teterow & 544.0 & 88.5 & 386.0 & 732.2 & 8.0 \\
3 & Hamburg & 770.3 & 113.1 & 540.2 & 998.4 & 8.4 \\
4 & Berlin & 583.8 & 102.5 & 384.1 & 788.0 & 8.9 \\
5 & Magdeburg & 494.0 & 110.1 & 302.9 & 694.8 & 8.1 \\
6 & Frankfurt & 657.8 & 152.5 & 367.6 & 1053.4 & 10.4 \\
7 & Bad Marienberg & 1168.7 & 244.5 & 752.2 & 1636.0 & 7.4 \\
8 & Nümberg & 644.2 & 117.9 & 400.1 & 908.6 & 7.9 \\
9 & Oberstdorf & 1908.4 & 515.7 & 1438.8 & 2460.3 & 6.2 \\
\hline
\end{tabular}

Table 2 German soil types used in this study.

\begin{tabular}{clccccc}
\hline No. & Soil type & Depth $(\mathrm{cm})$ & Sand (\%) & Clay (\%) & Org. carbon (\%) & pH \\
\hline 1 & Marshy Gleysol & 70 & 21 & 19 & 1.9 & 6.5 \\
2 & Podzol & 110 & 85 & 3 & 1.5 & 5.1 \\
3 & Luvisol & 100 & 6 & 11 & 1.0 & 6.5 \\
4 & Cambisol & 60 & 45 & 20 & 1.9 & 6.3 \\
5 & Rendzina & 30 & 18 & 25 & 2.2 & 7.5 \\
\hline
\end{tabular}

a) Upper soil horizon only.

Table 3 Combined Soil-Climate-Regions in Germany.

\begin{tabular}{clll}
\hline No. & \multicolumn{1}{c}{ Scenario } & $\begin{array}{l}\text { Representative } \\
\text { location (No.) }\end{array}$ & $\begin{array}{l}\text { Dominant soil } \\
\text { type (No.) }\end{array}$ \\
\hline 1 & North Sea coast & Schleswig (1) & Marshy Gleysol (1) \\
2 & Northern East Sea coast & Schleswig (1) & Cambisol (4) \\
3 & North eastern podzol region & Teterow (2) & Podzol (2) \\
4 & South eastern podzol region & Berlin (4) & Podzol (2) \\
5 & Western podzol region & Hamburg (3) & Podzol (2) \\
6 & Berlin region & Berlin (4) & Cambisol (4) \\
7 & Northern and north eastern loess region & Magdeburg (6) & Luvisol (3) \\
8 & Northern karst region & Bad Marienberg (7) & Rendzina (5) \\
9 & Western and south western loess region & Frankfurt (5) & Luvisol (3) \\
10 & Northern low mountain range & Bad Marienberg (7) & Cambisol (4) \\
11 & Southern karst region & Nürnberg (8) & Rendzina (5) \\
12 & Southern loess region & Nürnberg (8) & Luvisol (3) \\
13 & Southern low mountain range & Oberstdorf (9) & Cambisol (4) \\
\hline
\end{tabular}


WINSTAT-software (version 3.1 1995, Copyright Kalmia Co. Inc., German version by G. Greulich).

\section{RESULTS AND DISCUSSION}

\section{Analysis of Distribution}

At first the Monte-Carlo simulations have been analysed with regard to their distribution. A visualisation of some results is presented in the Figs. 1 and 2 for the German north eastern podzol region and for mean pesticide concentrations in the percolate of about 0.01 $\mu \mathrm{g} / l$. The histogram in Fig. 2 (log-normal distribution) fits well with the ideal curve whereas the histogram in Fig. 1 clearly does not show a normal-distribution. Similar results were also found for the other 12 regions. It was assumed that varying the climate parameters in leaching models like PELMO lead to log-normal distributions of pesticide concentrations in the leachate.

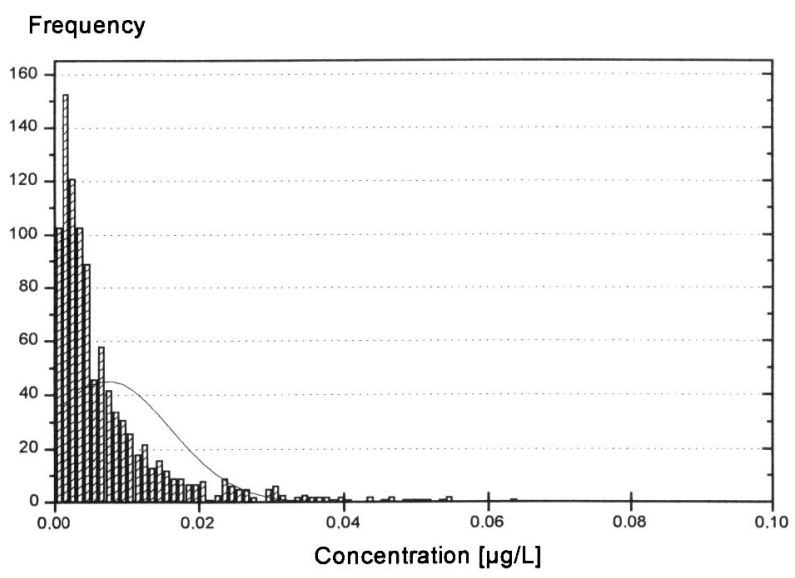

Fig. 1 Linear distribution of concentration in leachate. (German north eastern podzol region, spring application, mean concentration $0.01 \mu \mathrm{g} / l$ )

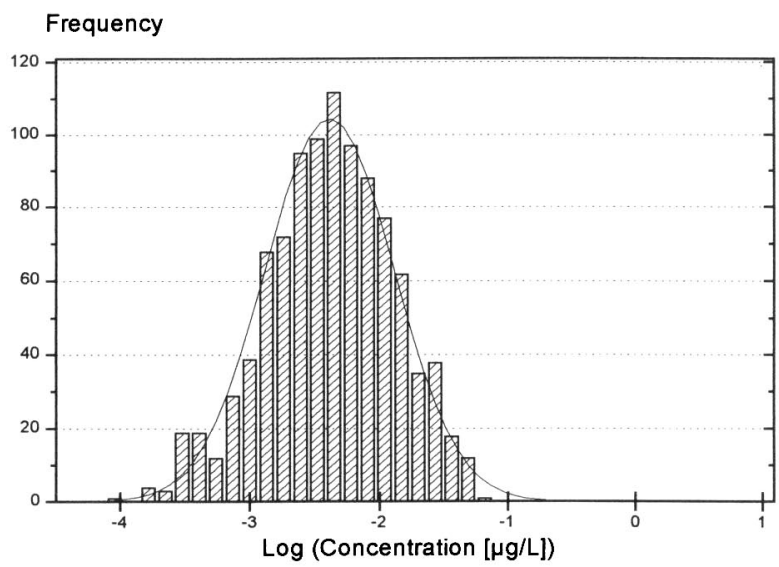

Fig. 2 Logarithmic distribution of concentration. (German north eastern podzol region, spring application, mean concentration $0.01 \mu \mathrm{g} / l$ )

\section{Influence of the Mean Concentration on the Fluctu- ations in Leachate}

Monte-Carlo simulations have been performed for three classes of pesticides with different leaching potentials. Some results are presented in the Figs. 3 and 4. The figures clearly show that the fluctuations of the concentrations decrease with increasing mean concentration in the leachate. This behaviour is not limited to the examples given in the figures: it can generally be stated that a low leaching potential (mean concentration in the leachate is small) will lead to a high fluctuation of concentration in the leachate due to the variation of climatic parameters. This was also observed by J.J.T.I. Boesten who performed similar model simulations for analysing the sensitivity of model input parameters. ${ }^{7)}$ He found differences in the maximum pesticide concentrations in leachate between two 5 and 10 for two different climatic scenarios (annual precipitation 860 and $600 \mathrm{~mm}$ ) dependent on the main pesticide concentration.

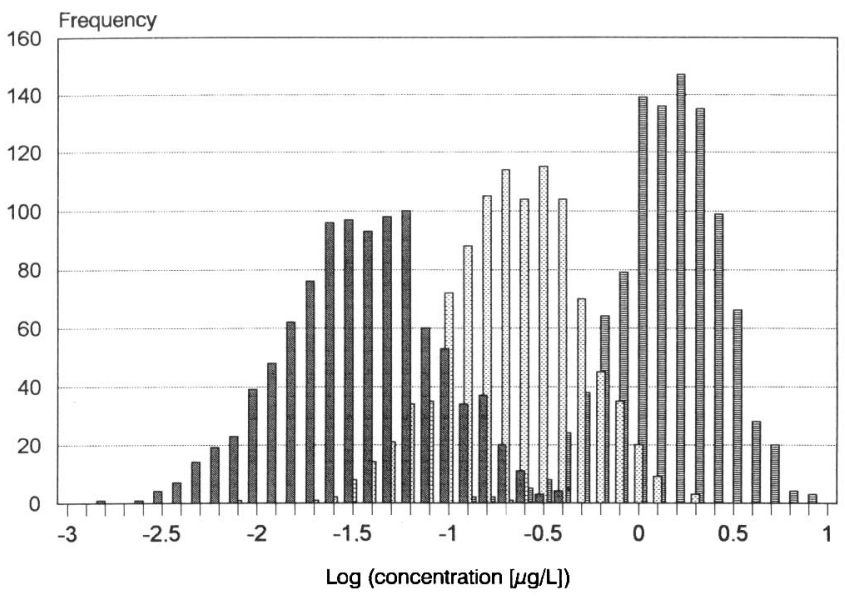

Fig. 3 Logarithmic distribution of concentration. (German southern karst region, spring application)

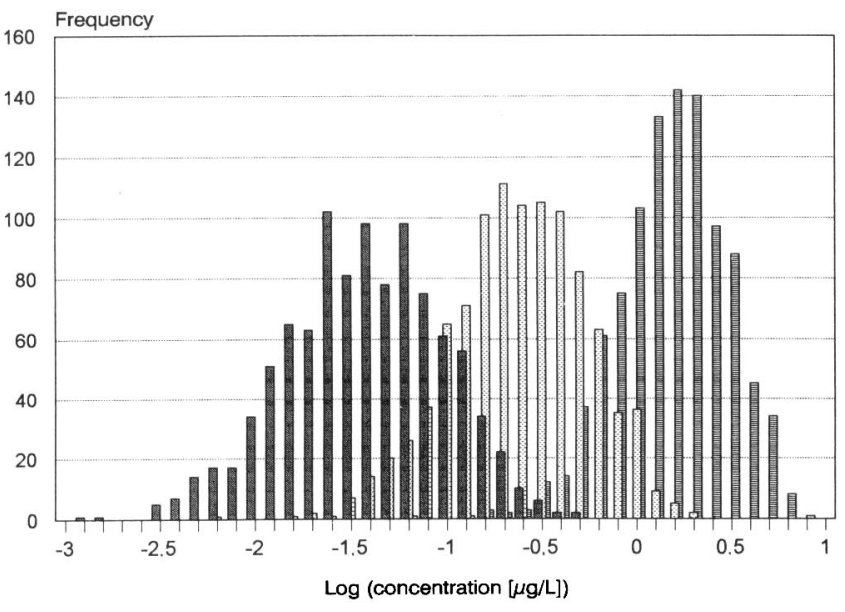

Fig. 4 Logarithmic distribution of concentration. (German southern karst region, autumn application) 
Because the calculated fluctuations were found to follow log-normal distributions, they were characterised by their geometric deviation. In order to find correlations between the logarithms of the geometric mean concentration and the logarithms of the geometric standard deviation linear regression analysis have been performed for all regions (according to Eq. 1).

$$
s_{\text {geom }}=s_{0}+b \cdot \log \left(c_{\text {mean }}\right)
$$

$s_{\text {geom: }}$ geometric standard deviation of pesticide concentration in leachate

$c_{\text {mean }}$ : geometric mean pesticide concentration in leachate $(\mu \mathrm{g} / l)$

$s_{0}$ : geometric standard deviation for mean pesticide concentration of $1.0 \mu \mathrm{g} / l$

$b$ : $\quad$ slope

The coefficients of the resulting straight lines are presented in Table 4. As indicated by the negative value of the slope $b$, the geometric standard deviation decreases with increasing mean pesticide concentration in the leachate for all regions. The value $s_{0}$, which is actually the geometric standard deviation for mean pesticide concentrations of $1.0 \mu \mathrm{g} / l$, was found to be between 1.6 and 2.4 dependent on the region.

Table 4 Pesticide input parameters used for the study.

\begin{tabular}{ll}
\hline \multicolumn{1}{c}{ Parameter } & Value \\
\hline Sorption constant $K_{\mathrm{Oc}}(\mathrm{ml} / \mathrm{g})$ & 40 \\
$\mathrm{DT}_{50}(\mathrm{~d})$ & 10 \\
$\mathrm{Henry}_{\text {constant }(\mathrm{Pa} / \mathrm{K} \mathrm{mol})}$ & 0 \\
Application rate $(\mathrm{kg} / \mathrm{ha})$ & 1.0 \\
Application datum & 1 st October \\
Mode of application & Every year \\
Target crop & Winter wheat \\
\hline
\end{tabular}

\section{Stochastic Analysis for an Example Pesticide}

Based on the results found for the 13 regions the fluctuations of mean pesticide concentrations caused by variations of climate can be estimated for any given pesticide. Table 4 shows the pesticide properties of an example that has been used to test the results for stochastic analyses.

Some results of the Monte-Carlo analysis are presented in Table 5. The analysis showed that dependent on the region a maximum factor of 30 could be found between mean concentrations and the 90 percentile. However, these extreme factors only occur for extreme low concentrations that can hardly be detected in the environment. If mean pesticide concentrations are simulated close to $0.1 \mu \mathrm{g} / l$, factors between the mean and the 90 percentile have to be expected that are close to 2 . However, differences between the 13 regions seem to be of much higher importance than fluctuations within these scenarios. Due to less precipitation and/or higher sorption capacity of the soils up to 10 orders of magnitude were found between the mean pesticide concentration in two regions (see the results for region 7 and 13 in Table 5). Obviously, beside stochastic modelling, also the spatial variability of input parameters have to be considered with more effort in the future. However, as this research has not been validated so far (e.g. using long term experimental data), it has not reached a status, that it can be used in the pesticide registration.

\section{CONCLUSION AND OUTLOOK}

In the past years the simulation of pesticide movement to groundwater has been analysed by various computer models. However, less attention has been paid to the question, in how far the leaching of pesticides is influenced by the variation of input parameters. It could be shown for a number of regions that log-normal distributions of pesticide concentrations in the percolate will occur, if the variation of climatic input parameters is

Table 5 Results of stochastic simulations with MCPELMO.

\begin{tabular}{clll}
\hline No. & \multicolumn{1}{c}{ Scenario } & $\begin{array}{c}\text { Mean conc. } \\
(\mu \mathrm{g} / l)\end{array}$ & $\begin{array}{c}90 \text { percentile } \\
(\mu \mathrm{g} / l)\end{array}$ \\
\hline 1 & North Sea coast & $1.67 \times 10^{-6}$ & $2.36 \times 10^{-5}$ \\
2 & Northern East Sea coast & $3.37 \times 10^{-4}$ & $8.68 \times 10^{-4}$ \\
3 & North eastern podzol region & $3.46 \times 10^{-5}$ & $1.38 \times 10^{-4}$ \\
4 & South eastern podzol region & 0.016 & 0.022 \\
5 & Western podzol region & 0.045 & 0.103 \\
6 & Berlin region & $2.71 \times 10^{-7}$ & $4.11 \times 10^{-6}$ \\
7 & Northern and north eastern loess region & $1.08 \times 10^{-10}$ & $3.22 \times 10^{-9}$ \\
8 & Northern karst region & 1.069 & 2.934 \\
9 & Western and south western loess region & 0.003 & 0.019 \\
10 & Northern low mountain range & 0.203 & 0.599 \\
11 & Southern karst region & $6.57 \times 10^{-4}$ & 0.001 \\
12 & Southern loess region & 0.000 & 0.000 \\
13 & Southern mountain range & 1.423 & 3.732 \\
\hline
\end{tabular}


considered. The simulations additionally showed, that the fluctuations of the concentrations decreased with increasing mean concentration in the leachate. Particularly the pesticides with low leaching potentials are more affected by climatic variations than pesticides that can be found in the leachate in high concentrations due to their properties. This result elucidates that there is a certain probability for groundwater findings also for pesticides with low leaching potentials that cannot be simulated when considering only mean weather conditions. Using the software package MCPELMO concentrations in leachate can be estimated for any pesticide and any given probability for at least 13 different regions in Germany.

However, a second result of this work may be that the spatial variability as considered roughly by the 13 German regions might be of higher importance than the variability with time within these regions that has been analysed in detail during this project. For spatial modelling of ground water concentrations a extremely high number of model input data have to be defined by overlaying different thematic maps (e.g. maps on the distribution of organic carbon, temperature or rainfall). In the following step computer simulations have to be performed either pixel by pixel or by using a suitable estimation method (in order to save computer time). Finally, the evaluation of the results have to be done, either again by drawing maps or by a statistical analysis showing the distribution of concentrations. However, it can be difficult to obtain the necessary input data as well as the appropriate level of resolution of themes in particular for larger areas, like Europe. Consistency of data, data quality and data availability will therefore be the main aspects for the success of exposure modelling with a spatial component. It can be expected that also the registration of pesticides will be influenced by this ongoing research.

\section{ACKNOWLEDGMENTS}

This research was supported by the Umweltbundesamt (German Federal Environmental Agency), Berlin. The support is gratefully acknowledged.

\section{REFERENCES}

1) FOCUS (Forum for International Coordination of Pesticide Fate Models and Their Use, ed.): "Leaching Models and EU Registration," EU DOC 4952/VI/95, Brussel, 1995

2) M. Klein: "PELMO Pesticide Leaching Model, version 2.01," Fraunhofer-Institut für Umweltchemie und Ökotoxikologie, D-57392 Schmallenberg, 1995

3) M. Klein, M. Müller, M. Dust, G. Görlitz, B. Gottesbüren, J. Hassink, R. Kloskowski, R. Kubiak, H. Resseler, H. Schäfer, B. Stein \& H. Vereecken: Validation of the pesticide leaching model PELMO using lysimeter studies performed for registration, Chemosphere 35, 2563-2587 (1997)

4) M. Klein: "Erweiterung von Expositionsmodellen auf der Basis von statistischen Umweltparametern," Report No. F 10602 089, German Environmental Protection Agency, Berlin (1996) (in German)

5) M. Klein: Statistical distribution of pesticide concentrations in leachate - results of a Monte-Carlo analysis performed with PELMO, Chemosphere 35, 379-389 (1997)

6) E. Beinat \& R. van den Berg (ed.): "EUPHIDS, a Decision Support System for the Admission of Pesticides," Environmental Research Programme of the European Communitiy, Direcorate-General for Science, Research, and Development contract No. EV5V-CT92-0217, available at RIVM, NL3720 BA Bilthoven, Report No. 712405002 (1996)

7) J.J.T.I. Boesten: Sensitivity analysis of a mathematical model for pesticide leaching to groundwater, Pestic. Sci. 31, 375-388 (1991) 